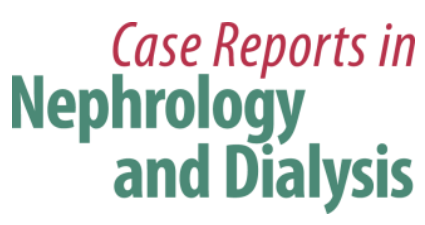

\title{
Peritoneal-Pleural Leaks Demonstrated by CT Peritoneography
}

\author{
Tian Xu Jingyuan Xie Weiming Wang Hong Ren Nan Chen \\ Department of Nephrology, Ruijin Hospital, Shanghai Jiao Tong University School of Medicine, \\ Shanghai, China
}

\section{Key Words}

Hydrothorax · Pleural effusion - Pleuroperitoneal communication · Computerized tomography peritoneography · Peritoneal dialysis · Dyspnea

\begin{abstract}
Introduction: Acute hydrothorax is an uncommon complication of peritoneal dialysis (PD) Currently, there is no specific diagnostic method. Although it is not a life-threatening complication, hydrothorax often requires interrupting or quitting PD. Misdiagnosis often leads to more serious consequences. Case Presentation: A 49-year-old woman (height $163 \mathrm{~cm}$, weight $58 \mathrm{~kg}$, BMI 21.82), who started PD 3 months previously, suddenly presented with acute dyspnea and a right pleural effusion. Blood routine examination, serum albumin and a series of laboratory tests were immediately performed. Except for the serum creatinine, all of the other tests were within normal range. Thoracentesis was performed to obtain pleural fluid specimens; there was also no evidence of a tumor or inflammation. Congestive heart failure, infection and hypoalbuminemia were excluded as well. Because PD-associated pleural leakage was suspected, computerized tomography (CT) peritoneography was performed next. The first CT scan showed that the CT value of pleural effusion was 6 Hounsfield units (HU). On the evening of the same day, $100 \mathrm{ml}$ ionic contrast medium was mixed with 2 I dialysate and infused into the peritoneal cavity. The next morning, a CT scan was performed again. The CT value of pleural effusion at the same site increased to $40 \mathrm{HU}$. At the end, pleural leakage was clearly diagnosed. Subsequently, she received temporary hemodialysis and a small dose of automated PD. After 3 months, she successfully returned to PD without any recurrence of hydrothorax. Conclusion: Although similar case reports are not rare, this report provided a simple and effective method for diagnosing pleural leakage. Furthermore, noninvasive treatment of pleural effusion will also get a satisfactory outcome. $\odot 2015 \mathrm{~s}$. Karger AG, Basel
\end{abstract}




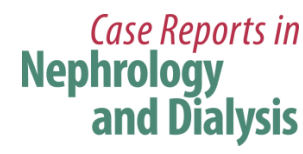

\begin{tabular}{l|l}
\hline \multicolumn{2}{l}{ Case Rep Nephrol Dial 2015;5:135-139 } \\
\hline DOI: 10.1159/000430806 & $\begin{array}{l}\text { @ 2015 S. Karger AG, Basel } \\
\text { www.karger.com/cnd }\end{array}$ \\
\hline
\end{tabular}

Xu et al.: Peritoneal-Pleural Leaks Demonstrated by CT Peritoneography

\section{Introduction}

Peritoneal dialysis (PD) is an effective treatment option for patients with end-stage renal disease. However, there are also various complications of PD. PD-related peritonitis is the most common complication, followed by catheter-related problems, hernia and dialysate leaks. PD-related hydrothorax was first reported in 1967 [1]. The reports of prevalence rates of hydrothorax vary, ranging from 1.6 to $10 \%$ of PD patients [2]. Usually, these patients present with sudden dyspnea, a decrease in ultrafiltration and chest pain. Some of them may remain asymptomatic or just complain of a dry cough [3]. An early and accurate diagnosis of pleural leakage is important. Unfortunately, there is still no effective and noninvasive method for the diagnosis. Searching for a simple and valid way to diagnose pleural leakage has become particularly important. MRI peritoneography was used to diagnose pleural leakage [3]. Here we report a case of pleural leakage, and it was diagnosed by CT peritoneography.

\section{Case Presentation}

A 49-year-old medium-sized woman (height $163 \mathrm{~cm}$, weight $58 \mathrm{~kg}$, BMI 21.82) with end-stage renal disease secondary to chronic glomerulonephritis started PD in December 2012. Polycystic kidney disease (PKD) had been excluded by the imaging examinations, and she also denied any family history of PKD. Usually, her blood pressure was slightly higher than normal (140 150/90 100 mm Hg). She was pregnant 20 years ago, but denied any history of traumatic injury to the chest or diaphragmatic surgery. A Tenckhoff catheter was inserted under local anesthesia. Two weeks after surgery, she commenced PD therapy. The PD prescription was the standard continuous ambulatory peritoneal dialysis (at daytime, $2 \mathrm{l}$ dialysate containing $1.5 \%$ glucose were indwelled for $3 \times 4 \mathrm{~h}$ and $2 \mathrm{l}$ dialysate containing $1.5 \%$ glucose overnight). At the initial period of PD, she did not feel any discomfort. However, 2 months later (February 15,2013 ), she suddenly presented with an onset of dyspnea associated with chest tightness. Before the onset of the above-mentioned symptoms, there had been no prodromal manifestation such as cough or constipation. Although the urine volume did not change significantly, the daily ultrafiltration volume sharply dropped from 1,000 to $300 \mathrm{ml}$. Upon physical examination, she experienced shortness of breath with a respiratory rate of 24 breaths per minute. Both breath sounds and tactile fremitus of the right lung field disappeared. The other vital signs, including body temperature and blood pressure, were normal. A chest radiography was performed immediately, and a moderate right pleural effusion was found (fig. 1a). Then, she was admitted to our hospital for evaluation and treatment of hydrothorax.

After having been admitted to our hospital, a series of laboratory tests and examinations were immediately performed. Except for the serum creatinine, all of the other tests were within normal range. The results of the evaluation showed the following: creatinine $765 \mu \mathrm{mol} / \mathrm{l}$, albumin $33 \mathrm{~g} / \mathrm{l}$, hemoglobin $115 \mathrm{~g} / \mathrm{l}$, white blood cells $6.6 \times 10^{9} / \mathrm{l}$, platelet count $221 \times 10^{9} / \mathrm{l}$, and a cardiac ejection fraction of $56 \%$. The dialysis adequacy was also satisfactory (Kt/V: 2.36 , Ccr: 63.26). A thoracentesis was performed in order to relieve the dyspnea and obtain pleural fluid specimens. The pleural fluid tests included: pleural fluid routine, bacterial culture, tumor markers, adenosine deaminase, etc. Pleural fluid biochemistry examinations showed transudate. Bacterial culture tests showed no evidence of infection. At the same time, there was no evidence of tumor or tuberculosis.

In order to obtain additional details on hydrothorax, a CT scan was performed. It showed right moderate pleural effusion (fig. 2a). We evaluated the Hounsfield units (HU) of the right pleural effusion; the CT value was $6 \mathrm{HU}$. On the evening of the same day, $100 \mathrm{ml}$ of ionic contrast medium was mixed with $2 \mathrm{l}$ of dialysate and infused into the peritoneal cavity via the Tenckhoff catheter. A CT scan was again performed the next morning (fig. $2 \mathrm{~b}, \mathrm{c}$ ). The scan spanned from the thorax to the pelvis. We re-evaluated the HU of the right pleural effusion and the peritoneal dialysate with iodine contrast medium in the pelvis. The CT value of the peritoneal dialysate in the pelvis was $150 \mathrm{HU}$, and the CT value of the right pleural effusion at the same site increased from 6 to $40 \mathrm{HU}$. We suspected that this change was associated with the movement of the contrast medium from the abdominal into the thoracic cavity. Thereafter, the patient stopped PD and transferred to hemodialysis. After that, the dyspnea and the chest tightness gradually disappeared. Three 


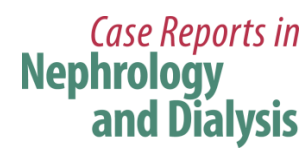

\begin{tabular}{l|l}
\hline Case Rep Nephrol Dial 2015;5:135-139 \\
\hline DOI: 10.1159/000430806 & $\begin{array}{l}\text { ○ 2015 S. Karger AG, Basel } \\
\text { www.karger.com/cnd }\end{array}$ \\
\hline
\end{tabular}

Xu et al.: Peritoneal-Pleural Leaks Demonstrated by CT Peritoneography

months later, the patient once again received a chest radiography, which showed that the right hydrothorax had been completely absorbed (fig. 1b). She utilized automated peritoneal dialysis to resume PD. The dialysis dose in each cycle was $500 \mathrm{ml}$, and the total dialysis dose per day was 6 l. Subsequently, the dose in each cycle increased by $500 \mathrm{ml}$ weekly until $2 \mathrm{l}$, and the daily total dialysis dose was maintained at $6 \mathrm{l}$. So far, there has been no recurrence of hydrothorax.

\section{Discussion}

Hydrothorax due to the migration of dialysis fluid from the abdominal space into the pleural space creates a serious complication of PD; it is normally not life-threatening. Previously, a variety of mechanisms for hydrothorax had been reported (congenital diaphragmatic defects, pleuroperitoneal pressure gradients, lymph drainage disorders and acquired anatomic defects) [1, 4-6]. The PD patients with secondary PKD may have a higher risk of hydrothorax. Because of the large kidneys and an inherent defect in the diaphragm, the average intraabdominal pressure may be much higher than that in patients with a normal condition [7]. Previously pregnant women are also at higher risk. The exact cause is unclear, but possibly the stretching of the diaphragm from a previous pregnancy could be a factor [8]. Hydrothorax is almost always on the right side [9]. Our patient also suffered from right pleural effusion. The presence of the heart and pericardium may play a preventive role in left pleural effusion. Coughing and stretching are the common cause of pleural defects or hernia the intraabdominal pressure reaches $120-150 \mathrm{~cm} \mathrm{H}_{2} \mathrm{O}$ when coughing or straining, compared to $0.5-2.2 \mathrm{~cm} \mathrm{H}_{2} \mathrm{O}$ in the normal condition). The pressure in patients with peritoneal fluid is just 2-10 $\mathrm{cm} \mathrm{H}_{2} \mathrm{O}$ [10].

Hydrothorax frequently presents as shortness of breath or even dyspnea, the disappearance of breath sounds as well as tactile fremitus; approximately $25 \%$ of patients remain asymptomatic [11]. Symptoms such as the ones mentioned above can be mistaken as congestive heart failure, pulmonary infection, hypoalbuminemia, inadequate dialysis and so on. So the related tests and examinations should immediately be performed for a differential diagnosis. In the case of our patient, the tests did not support a diagnosis of these diseases.

Based on the above normal test results and the time of manifestation, pleural leakage, which classically has an early onset after the commencement of PD, was suspected. In order to obtain additional details on hydrothorax, further imaging studies should be done. However, all previous studies assessing imaging techniques had a very small subject number, and none of the test methods was highly sensitivity. For example, the sensitivity of radionuclide scans (such as Tc-99m DTPA) was between 40 and 50\% [12,13]. CT and MRI are also commonly used diagnostic techniques. Kang and Kim [14] reported that CT peritoneography can not only diagnose pleuroperitoneal communication, but also locate the position of the leakage. However, contrast CT peritoneography was associated with a 33\% sensitivity in another study and added the risk of nephrotoxicity in those with residual renal function [12, 13]. Although the leakage location could not be located in this case, pleuroperitoneal communication was definitively diagnosed through CT peritoneography. In recent years, video-assisted thoracic surgery [15-17] has been applied more often. It allows the visualization of the pleura and the diaphragm to identify possible defects.

There are a lot of ways of treating pleuroperitoneal communication. First of all, PD should be interrupted for a period of time. Resting the membrane for at least 4-6 weeks will allow the mesothelium to reconstitute itself over the defect, and the pleuroperitoneal communication may reseal. A temporary interruption of PD was associated with a $53 \%$ success rate in resuming PD [4]. Furthermore, invasive procedures like pleurodesis and thoracotomy as well as video-assisted thoracic approaches can be applied if the conservative treatment is 
Xu et al.: Peritoneal-Pleural Leaks Demonstrated by CT Peritoneography

failing. After 3 months of conservative treatment, our patient restarted PD. Until now, there has been no recurrence of hydrothorax. Nearly $60 \%$ of patients with pleural defects resume maintenance PD after either conservative or interventional treatment [18], but the others have to permanently transfer to hemodialysis.

PD-related hydrothorax should be recognized and treated timely, although most of the diagnostic strategies that confirm it are unsatisfactory, CT peritoneography provides a noninvasive and useful diagnostic tool for pleuroperitoneal communication. Conservative treatment generally precedes invasive intervention. The discontinuation of PD for a few weeks often leads to the successful resolution of hydrothorax.

\section{Disclosure Statement}

On behalf of Dr. Chen Nan and the other authors, we declare that no financial or other conflict of interest exists in relation to the content of the paper.

\section{References}

1 Edward SR, Unger AM: Acute hydrothorax: a new complication of peritoneal dialysis. JAMA 1967;199:853855.

2 Lew SQ: Hydrothorax: pleural effusion associated with peritoneal dialysis. Perit Dial Int 2010;30:13-18.

3 Kay H, Doreen R, Thomas K, Peter G: Dry cough in a CAPD patient. Nephrol Dial Transplant 2003;18:10271029.

4 Chow KM, Szeto CC, Li PK: Management options for hydrothorax complicating peritoneal dialysis. Semin Dial 2003;16:389-394.

5 Yim AP, Lee TW, Wan IY, Ng C: Images in cardiothoracic surgery. Pleuroperitoneal fistula. Ann Thorac Surg 2003;73:1327.

6 Saillen P, Mosimann F, Wauters JP: Hydrothorax and end-stage chronic renal failure. Chest 1991;99:10101011.

7 Fletcher S, Tumey JH, Brownjohn AM: Increased incidence of hydro-thorax complicating peritoneal dialysis in patients with adult polycystic kidney disease. Nephrol Dial Transplant 1994;9:832-833.

8 Saha TC, Singh H: Noninfectious complications of peritoneal dialysis. South Med J 2007;100:54-58.

9 Grefberg N, Danielson BG, Benson L, Pitkanen P: Right-sided hydro-thorax complicating peritoneal dialysis. Report of 2 cases. Nephron 1983;34:130-134.

10 Mahale AS, Katyal A, Khanna R: Complications of peritoneal dialysis related to increased intra-abdominal pressure. Adv Perit Dial 2003;19:130-135.

11 Nomoto Y, Suga T, Nakajima K, Sakai H, Osawa G, Ota K: Acute hydrothorax in continuous ambulatory peritoneal dialysis - a collaborative study of 161 centers. Am J Nephrol 1989;9:363-367.

12 Tang S, Chui WH, Tang AW, Li FK, Chau WS, Ho YW, Chan TM, Lai KN: Video-assisted thoracoscopic talc pleurodesis in effective for maintenance of peritoneal dialysis in acute hydrothorax complicating peritoneal dialysis. Nephrol Dial Transplant 2003;18:804-808.

13 Pankaj P, Pathak V, Sen IB, Verma R, Bhalla AK, Marwaha A, Pandey S: Use of radionuclide peritoneography in the diagnosis of pleuroperitoneal communication as a complication of continuous ambulatory peritoneal dialysis. Ind J Nucl Med 2005;20:4-8.

14 Kang TW, Kim CK: Pleuroperitoneal communication of peritoneal dialysis demonstrated by multidetectorrow CT peritoneography. Abdom Imaging 2009;34:780-782.

15 Fernando SK, Salzano R, Reynolds JT: Peritoneal dialysis-related hydrothorax-case report. Adv Perit Dial 2006;22:158-161.

16 Lang CL, Kao TW, Lee CM, Tsai CW, Wu MS: Video-assisted thoracoscopic surgery in continuous ambulatory peritoneal dialysis-related hydrothorax. Kidney Int 2008;74:136.

17 Cho Y, D'Intini V, Ranganathan D: Acute hydrothorax complicating peritoneal dialysis: a case report. J Med Case Rep 2010;4:355.

18 Green A, Logan M, Medawar W, McGrath F, Keeling F, Carmody M: The management of hydrothorax in continuous ambulatory peritoneal dialysis (CAPD). Perit Dial Int 1990;10:271-274. 


\section{Case Reports in \\ Nephrology \\ and Dialysis}

\begin{tabular}{l|l}
\hline \multicolumn{2}{l}{ Case Rep Nephrol Dial 2015;5:135-139 } \\
\hline DOI: 10.1159/000430806 & $\begin{array}{l}\text { @ 2015 S. Karger AG, Basel } \\
\text { www.karger.com/cnd }\end{array}$ \\
\hline
\end{tabular}

Xu et al.: Peritoneal-Pleural Leaks Demonstrated by CT Peritoneography
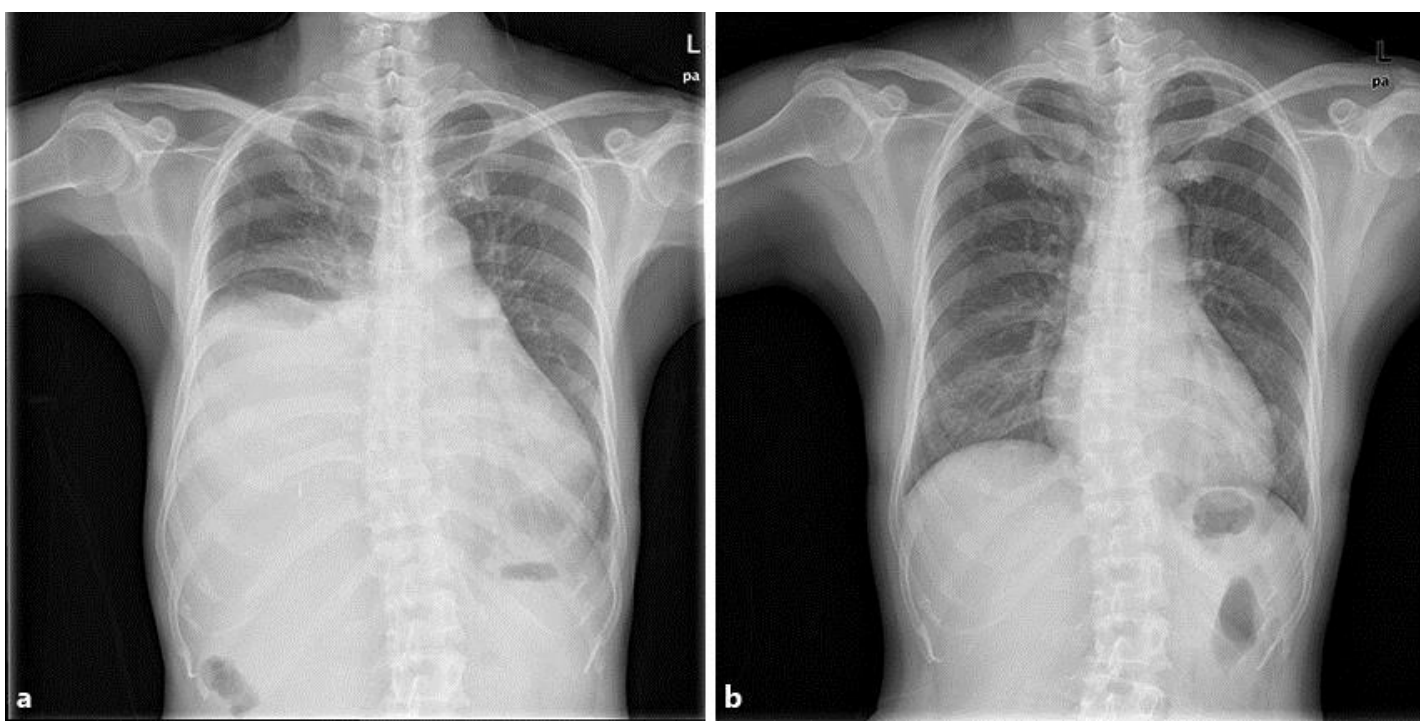

Fig. 1. Chest radiography. a A female patient presented with sudden onset of dyspnea associated with chest tightness. A chest radiography was immediately performed, and a moderate right pleural effusion was found. $\mathbf{b}$ Three months later, the chest radiography showed that the right hydrothorax had been completely absorbed.
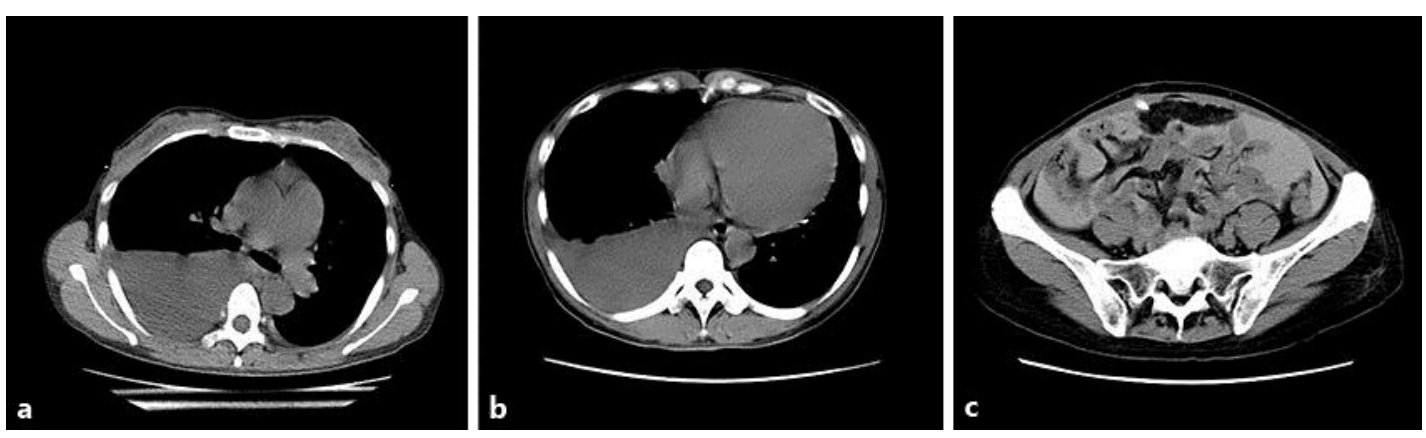

Fig. 2. Chest and pelvis CT scans. a The first CT scan showed right moderate pleural effusion, and the CT value of the right pleural effusion was $6 \mathrm{HU}$. On the evening of the same day, $100 \mathrm{ml}$ of ionic contrast medium was mixed with $2 \mathrm{l}$ dialysate and infused into the peritoneal cavity. The next morning, a CT scan was again performed. $\mathbf{b}$ The CT value of the right pleural effusion at the same site increased from 6 to $40 \mathrm{HU}$. c The CT value of the peritoneal dialysate in the pelvis was $150 \mathrm{HU}$. 